\title{
Editorial: Flooding on Coral Reef-Lined Coasts: Current State of Knowledge and Future Challenges
}

\author{
William Skirving ${ }^{1,2}$, Andrew Pomeroy ${ }^{3,4}$, Robert McCall ${ }^{5}$, John Marra ${ }^{6}$ and Curt Storlazzi ${ }^{7 *}$ \\ ${ }^{1}$ Coral Reef Watch, National Oceanic and Atmospheric Administration, College Park, MD, United States, ${ }^{2}$ ReefSense Pty \\ Ltd., Cranbrook, QLD, Australia, ${ }^{3}$ Oceans Institute, University of Western Australia, Perth, WA, Australia, ${ }^{4}$ Australian Institute \\ of Marine Science, Perth, WA, Australia, ${ }^{5}$ Unit of Marine and Coastal Systems, Deltares, Delft, Netherlands, ${ }^{6}$ National \\ Environmental Satellite, Data and Information Service (NESDIS) National Centers for Environmental Information, National \\ Oceanic and Atmospheric Administration, Honolulu, HI, United States, ${ }^{7}$ Pacific Coastal and Marine Science Center, U.S. \\ Geological Survey, Santa Cruz, CA, United States
}

Keywords: sea level, waves, beaches, sediment transport, runup, flood, inundation, coastal resilience

\section{Editorial on the Research Topic}

\section{Flooding on Coral Reef-Lined Coasts: Current State of Knowledge and Future Challenges}

Many low-lying, tropical, coral reef-lined coasts and islands are experiencing wave-driven flood events that currently strike with little to no warning. These events are a result of a combination of sea surface elevation and wave height, and can cause severe flooding even on windless, sunny days. With rising sea levels, over the coming decades, coastal flooding in all its forms will have significantly increased impacts. Increasing the resilience of coastal communities while decreasing the risk to lives and livelihood is critical in these locations.

Understanding and predicting coastal flooding is therefore a challenging and urgent problem.

Edited and reviewed by: Marta Marcos,

University of the Balearic Islands, Spain

*Correspondence: Curt Storlazzi cstorlazzi@usgs.gov

Specialty section: This article was submitted to Coastal Ocean Processes, a section of the journal Frontiers in Marine Science

Received: 30 November 2020 Accepted: 07 December 2020 Published: 07 January 2021

Citation:

Skirving W, Pomeroy A, McCall R,

Marra J and Storlazzi C (2021)

Editorial: Flooding on Coral Reef-Lined Coasts: Current State of Knowledge and Future Challenges.

Front. Mar. Sci. 7:635240. doi: 10.3389/fmars.2020.635240
Although this issue is global in scale, understanding and predicting flooding along tropical, coral reef-lined shorelines presents unique challenges owing to the complexity of these shorelines, which have been little studied and for which there are few data.

To address the urgent need for coastal flooding early warning system (EWS) and future scenario modeling tools, the UFORIC (Understanding Flooding on Reef-lined Island Coasts; https://geoblueplanet.org/blue-planet-activities/uforic/) working group was established in 2018. This group has committed to meet regularly to advance and update work plans. The ultimate goal of this working group is to develop the tools and research that aid disaster risk management and climate change adaptation in coral reef-lined coasts. Such developments require a multidisciplinary research effort, and thus the UFORIC working group includes leading coastal engineers, physical oceanographers, geologists, geographers, ecologists, remote-sensing specialists, and climate-change scientists.

The first UFORIC workshop was held in Hawaii during February 2018. Apart from an improved level of cooperation and collaboration within the community, a number of outcomes have been realized since the workshop, including but not limited to: A workshop report, published in EOS (Storlazzi, 2018); a paper that summarizes the "Steps to Develop Early Warning Systems and Future Scenarios of Storm Wave-driven Flooding Along Coral Reef-lined Coasts" (published in this Research Topic: Winter et al.), the formation of the Wave-driven Flood-forecasting on Reeflined Coasts Early warning system (WaveFoRCE) project (https://geoblueplanet.org/waveforce/), and the creation of this Frontiers in Marine Science Research Topic.

This Research Topic has 8 papers that address a number of the key aspects of the UFORIC goals, which if realized, will lead to the development of tools to accurately predict wave-driven flooding on 
the order of days, and the development of scenario methodologies, leading to long-term projections of wave-driven flooding on the order of decades.

These key aspects are described in Winter et al. and include an improved understanding of (1) sea level (tidal and nontidal residuals); (2) offshore wave conditions; (3) nearshore waves and wave-driven water levels; (4) reef accretion, sediment production and reef-to-shore transport; and (5) the development of sedimentary coasts. While 1,2, and 3 are key for the development of coastal flooding in a short-term forecast, an understanding of all 5 aspects are necessary for the development of future scenarios.

The importance of points 1-3 above are highlighted by Hoeke et al., who compare and contrast flooding events on Tuvalu and Kiribati to identify contributions of regional sea level variations and wave-driven processes to reef-island flooding. Cheriton et al. further our understanding of nearshore waves on reeflined coasts by studying the occurrence and characteristics of infragravity and very-low frequency waves at seven sites in the Pacific, representing a range of reef geometries. Lastly, Wandres et al. investigate the potential of existing numerical, statistical and empirical models to reproduce wave-driven nearshore hydrodynamics observed on Fiji's Coral Coast. All three papers have implications for the way in which EWS should be set up, as well as for the assessment of the effects of climate change on future flood risk.

Processes that contribute to, shape and influence shallow water bathymetry and beach profiles are discussed by Rosenberger et al., who describe a hydrodynamics and sediment transport study on a fringing reef/lagoon complex in Western Australia. Risandi et al. investigate the influence of reefs on hydrodynamics and how this shapes and modifies the shoreline as offshore waves and water levels vary, by studying a pocket beach in southwestern Australia. David and Schlurmann continue this line of research by investigating the influence of hydrodynamic drivers and their role in the changing sediment volumes of reefs, by studying the sand spit Thoondu, located on Fuvahmulah, Maldives.

The studies described above highlight the variation in coral reef morphology and the role reef morphology has on nearshore

\section{REFERENCES}

Storlazzi, C. D. (2018). Challenges of forecasting flooding on coral reef-lined coasts. Eos 99. doi: 10.1029/2018EO098517

Conflict of Interest: WS is employed by ReefSense Pty Ltd, and RM is employed by Deltares.

The remaining authors declare that the research was conducted in the absence of any commercial or financial relationships that could be construed as a potential conflict of interest. hydrodynamics and coastal flooding. Structuring coral reef variability into information that is useful for coastal flooding modeling and EWS is the topic of the contribution of Scott et al. to the Research Topic. In this paper, they describe how they have simplified a large dataset of measured coral reef topobathymetric cross-shore profiles $(>30,000)$ using machine learning and numerical modeling, to develop a set of representative cluster profiles that can accurately be used to describe hydrodynamics (e.g., wave runup) at the shoreline. This technique lends itself to use in global EWS systems such as that being developed by the WaveFoRCE team.

Although only a subset of the knowledge necessary for short term forecasting of wave-driven flood events on coral reef-lined coasts, and the development of accurate long term scenarios, the papers in this Research Topic contribute valuable knowledge to this field. They also provide an insight into the highly complex science behind successful prediction of wave-driven flooding on coral reef-lined coasts throughout the world.

\section{AUTHOR CONTRIBUTIONS}

All authors listed have made a substantial, direct and intellectual contribution to the work, and approved it for publication.

\section{FUNDING}

This work was partially supported by the U.S. Geological Survey's Coastal and Marine Hazards and Resources Program, NOAA grant NA19NES4320002 (Cooperative Institute for Satellite Earth System Studies) at the University of Maryland/ESSIC, and the U.S. Department of Defense's Strategic Environmental Research and Development Program. The scientific results and conclusions, as well as any views or opinions expressed herein, are those of the author(s) and do not necessarily reflect the views of NOAA or the Department of Commerce.

\section{ACKNOWLEDGMENTS}

We thank all authors, reviewers, and editors who have contributed to this Research Topic. Copyright (c) 2021 Skirving, Pomeroy, McCall, Marra and Storlazzi. This
is an open-access article distributed under the terms of the Creative
Commons Attribution License (CC BY). The use, distribution or reproduction
in other forums is permitted, provided the original author(s) and the
copyright owner(s) are credited and that the original publication in this
journal is cited, in accordance with accepted academic practice. No use,
distribution or reproduction is permitted which does not comply with these
terms. 